\title{
Tamanho da amostra para quantificação do diâmetro de lesões de cancro cítrico
}

\author{
José Belasque Jr. ${ }^{1}$, Fabrício José Jaciani² ${ }^{2}$ Denis Rogério Marin ${ }^{1}$ \& José Carlos Barbosa ${ }^{3}$ \\ ${ }^{1}$ Departamento Científico, Fundecitrus, 14807-040, Araraquara, SP, Brasil; ${ }^{2}$ Departamento de Tecnologia; ${ }^{3}$ Departamento de \\ Ciências Exatas, Universidade Estadual Paulista - UNESP, 14884-900, Jaboticabal, SP, Brasil
}

Autor para correspondência: José Belasque Jr., e-mail: belasque@fundecitrus.com.br

\begin{abstract}
RESUMO
A estimativa do diâmetro de lesões de cancro cítrico é uma das principais técnicas usadas na avaliação da interação entre isolados x genótipos, na avaliação da resistência varietal e no estudo de aspectos epidemiológicos. No entanto, inexistem informações a respeito do tamanho da amostra para uma adequada quantificação da doença, considerando o diâmetro de lesões. Nesse sentido, o presente trabalho teve como objetivo a determinação do número de amostras para mensurar o diâmetro médio de lesões de cancro cítrico. Foram considerados como fontes de variação três genótipos do hospedeiro, dois métodos de inoculação de Xanthomonas citri subsp. citri e dois avaliadores. As avaliações dos diâmetros foram realizadas considerando ou não o halo amarelo ao redor do tecido necrosado, quando presente. Estimativas do diâmetro de lesões com erros na média inferiores a 3\% são impraticáveis em razão do tamanho excessivo da amostra (mais que quarenta lesões/planta). Menores erros na média ocorreram nas estimativas considerando somente o tecido necrosado. Estimativas precisas do diâmetro de lesões, com erros na média inferiores a $10 \%$, podem ser obtidas com tamanhos de amostras entre cinco e quinze lesões/planta, independentemente do genótipo e da idade das lesões.
\end{abstract}

Palavras-chave: Xanthomonas citri subsp. citri, fitopatometria, citros.

\section{ABSTRACT}

Size of sample to determine the diameter of lesions of citrus canker

The estimation of lesion diameter of citrus canker is one of the most common parameters used in the evaluation of the interaction of strains x genotypes, host resistance, and epidemiology. However, there is no information indicating the sample size for adequate disease measurement, considering the diameter of lesions. In the present work, our objective was to determine the number of samples needed to estimate the diameter of citrus canker lesions. The following factors of variation were considered: three host genotypes, two methods of inoculation, and two evaluators. The diameter evaluations were made considering, or not, the yellow halo, when present. Estimates of lesion diameter with average errors smaller than 3\% are impracticable because of the excessive sample size (at least forty lesions/plant). Smaller errors occurred when only the necrosis was considered during the evaluations. Precise estimates of lesion diameter, with errors smaller than $10 \%$, are achieved with sample size between five and fifteen lesions/plant, independently of the citrus genotype and age of lesions.

Keywords: Xanthomonas citri subsp. citri, phytopathometry, citrus.

O cancro cítrico, causado por Xanthomonas citri subsp. citri (Schaad et al., 2006), é uma das mais importantes doenças dos citros (Stall \& Seymour, 1983; Gottwald et al., 2002). Os sintomas constituem-se em lesões necróticas, às vezes circundadas por halos amarelos, presentes em folhas, ramos e frutos. Infecções severas podem induzir desfolha, queda de frutos e morte de ramos (Stall \& Seymour, 1983). Sob condições naturais de infecção, a disseminação a curtas distâncias ocorre principalmente pela ação de respingos de chuvas e de chuvas associadas com ventos e a disseminação a longas distâncias dá-se pelo transporte de material vegetal infectado (Gottwald et al., 1989; Massari \& Belasque Jr., 2006). O comércio mundial impõe restrições à importação de cítricos originários de países ou regiões com cancro cítrico, sendo esta uma doença quarentenária nos principais países produtores (Gottwald et al., 2002).

Como descrito por Belasque Jr. \& Bergamin
Filho (2006), o controle do cancro cítrico pode ser generalizadamente dividido: a) na adoção de medidas de exclusão e erradicação, princípios utilizados em regiões que possuem campanhas oficiais de erradicação do patógeno, como exemplo o estado de São Paulo (Barbosa et al., 2001; Massari \& Belasque Jr., 2006); e b) no manejo da doença pela combinação de genótipos resistentes ou moderadamente resistentes, fungicidas cúpricos e cortinas quebra-ventos, estratégias utilizadas em regiões nas quais o cancro cítrico é endêmico, ou mesmo que recentemente interromperam suas campanhas de erradicação (Leite Jr. et al., 1987). Ressalta-se que essa divisão é bastante generalizada, pois tanto regiões que empregam medidas de exclusão/erradicação podem fazer uso de cortinas quebra-vento, pulverizações cúpricas, ou genótipos resistentes, entre outras, quanto o contrário (Belasque Jr. \& Bergamin Filho, 2006). De qualquer maneira, para ambas as situações, a geração de genótipos 
resistentes, seja por melhoramento genético ou mesmo pela avaliação de bancos de germoplasmas, deve ser considerada uma das prioridades em programas de pesquisa com cancro cítrico. $\mathrm{O}$ advento de técnicas que permitem a manipulação e inserção de DNA em genomas hospedeiros em muito auxilia a geração de genótipos resistentes. Dessa forma, as pesquisas envolvendo resistência varietal ao cancro cítrico foram intensificadas nos últimos anos (Viloria et al., 2004; Azevedo, 2005; Pavan, 2006).

A estimativa do diâmetro de lesões de cancro cítrico é uma das principais técnicas usadas na avaliação da interação entre Xanthomonas citri subsp. citri x genótipos (Graham \& Gottwald, 1990; Nociti et al., 2006;), na avaliação da resistência varietal (Garran, 1988), e no estudo de aspectos epidemiológicos (Gottwald et al., 1997). Graham \& Gottwald (1990) verificaram correlação significativa na comparação dos diâmetros de lesões de cancro cítrico induzidas em plantas mantidas em campo e casa-de-vegetação, assim como entre a população bacteriana em lesões e seus respectivos diâmetros médios. O mesmo foi verificado por Egel et al. (1991) na comparação de populações bacterianas e diâmetros de lesões. Da mesma forma, a técnica de inoculação de Xanthomonas patogênicas em citros por ferimentos com agulhas é mais efetiva que a inoculação por aspersão ou infiltração na determinação da suscetibilidade de genótipos e no estudo da interação patógeno-hospedeiro (Garran, 1988; Graham \& Gottwald, 1990; Egel et al., 1991; Belasque Jr. \& Jesus Jr., 2006; Nociti et al., 2006).

Portanto, em estudos envolvendo resistência de genótipos de citros e/ou a interação patógeno-hospedeiro um sistema que pode ser utilizado envolve a inoculação por ferimentos com agulhas e a avaliação dos diâmetros de lesões, dependendo dos objetivos da pesquisa. Isso permite a realização de estudos mais rápidos, de menor custo, e com maiores números de plantas ou repetições, dentre outras vantagens, aspectos importantes principalmente na seleção de genótipos quanto à resistência ao cancro cítrico (Viloria et al., 2004). No entanto, inexistem informações a respeito do tamanho da amostra para uma adequada quantificação da doença. Nesse sentido, o presente trabalho teve como objetivo a determinação do número de amostras para mensurar o diâmetro médio de lesões de cancro cítrico. Para isso foram considerados como fontes de variação três genótipos do hospedeiro, dois métodos de inoculação da bactéria agente causal do cancro cítrico e dois avaliadores. As avaliações foram realizadas em três datas diferentes e os diâmetros mensurados considerando ou não o halo amarelo ao redor do tecido necrosado, quando presente.

Mudas de laranjas doces 'Pêra Rio' e 'Hamlin' (Citrus sinesis) e tangerina 'Ponkan' (C. reticulata) foram cultivadas em casa-de-vegetação em vasos de seis litros contendo terra e substrato orgânico (1:1). As plantas foram podadas aproximadamente cinqüenta dias antes da inoculação, para obtenção de folhas homogêneas e imaturas, entre 75 e 100\% da completa expansão foliar (Viloria et al., 2004). O inóculo foi preparado a partir de cultura pura de Xanthomonas citri subsp. citri (Xcc) (isolado IBSBF 1421), semeada em meio de cultura nutriente ágar por 72 horas a $28^{\circ} \mathrm{C}$. Diluições seriadas em tampão fosfato $(0,075 \mathrm{M}, \mathrm{pH} 7,0)$, a partir de suspensão bacteriana ajustada a $10^{8}$ unidades formadoras de colônia/mL (UFC/mL) em espectrofotômetro a $600 \mathrm{~nm}$, resultaram na concentração de inóculo a $10^{6} \mathrm{UFC} / \mathrm{mL}$. Foram empregados dois métodos de inoculação: a) ferimento do limbo foliar com agulha de $0,55 \times 0,20 \mathrm{~mm}$ imediatamente após a imersão da mesma na suspensão bacteriana. Foram realizadas seis perfurações/folha e inoculadas dez folhas/ planta; b) aspersão da suspensão bacteriana com compressor/ aspirador de ar, com uma pressão de aproximadamente 15 $\mathrm{lbf} / \mathrm{pol}^{2}$, até o ponto de escorrimento, em todas as folhas das plantas. Para ambos os métodos de inoculação as plantas permaneceram em câmara úmida por aproximadamente vinte horas após a inoculação. Para cada genótipo e tipo de inoculação foram empregadas quatro plantas (repetições). Durante todo experimento as plantas foram mantidas em casa-de-vegetação, sob temperaturas entre 13 e $35^{\circ} \mathrm{C}$.

As avaliações dos diâmetros das lesões de cancro cítrico foram realizadas por dois avaliadores aos 56, 70 e 83 dias após a inoculação (DAI). Para a mensuração dos diâmetros os avaliadores utilizaram micrômetros, tendo sido previamente treinados no uso do equipamento. Em cada data de avaliação foram mensurados os diâmetros de todas as lesões presentes nas quatro plantas de cada genótipo e para cada tipo de inoculação. Em razão da presença de halo amarelo ao redor do tecido necrosado, na maioria das avaliações, cada lesão foi mensurada duas vezes por cada avaliador, tendo-se considerado (ou não) o halo na determinação do tamanho da lesão. Para fins de padronização somente foram realizadas medidas de diâmetro na superfície adaxial das folhas.

As fontes de variação consideradas foram três genótipos, dois métodos de inoculação, dois avaliadores e presença ou não do halo amarelo ao redor do tecido necrosado. $\mathrm{O}$ delineamento experimental foi inteiramente casualizado. Os diâmetros médios correspondentes às lesões induzidas em plantas relativas a cada um desses fatores, nas três datas de avaliação, foram comparados entre si, dentro de cada fonte de variação, por análise de variância (teste F) e teste de médias (Tukey HSD, 5\%). O número de amostras foi determinado considerando $1,2,3 \ldots 20 \%$ de erro na média dos diâmetros das lesões. Nessa determinação foram eliminados os efeitos de genótipos, métodos de inoculação e avaliadores. O número de amostras foi calculado para cada data de avaliação, e para as três datas conjuntamente, para diâmetros mensurados com e sem halo amarelo. As análises foram feitas com auxílio do software SAS - Statistical Analysis System (SAS Institute, Cary, NC, USA).

Os sintomas foram observados nas plantas inoculadas por ferimentos entre uma e duas semanas após a inoculação, e entre duas a três semanas nas plantas inoculadas por aspersão. Os métodos de inoculação de Xcc diferiram entre si quanto ao diâmetro das lesões. O método de inoculação por ferimentos sempre resultou em diâmetros maiores. Não foram observadas lesões com halo amarelo resultantes da 
inoculação por aspersão nas duas primeiras avaliações, aos 56 e 70 DAI, mas essas foram visualizadas na avaliação aos 83 DAI (Tabela 1). Diferenças entre os genótipos foram observadas aos 56 e 83 DAI na mensuração das lesões com halo amarelo, e em todas as avaliações para lesões sem halo. Menores lesões foram sempre observadas nas plantas de tangerina 'Ponkan', enquanto 'Pêra Rio' e 'Hamlin' diferiram entre si somente aos 83 DAI. Os avaliadores diferiram entre si apenas em dois momentos, aos 70 DAI para lesões sem halo amarelo e aos 83 DAI para lesões com halo, tendo o avaliador 2 determinado maiores diâmetros em ambas as datas.

O número de lesões para determinação de diâmetros com erros na média entre 1 e $20 \%$ variou de 1.229 a 1, respectivamente (Tabela 2). Menores amostras corresponderam a mensurações sem o halo amarelo, para mesmos valores de erros em comparação com diâmetros com halo. De modo geral, pequenas variações ocorreram, quanto ao tamanho da amostra, entre as datas de avaliação. Considerando todas as datas de avaliação, para erros na média de $10 \%$, por exemplo, doze lesões devem ser mensuradas, quando com halo amarelo, e seis lesões para avaliações desconsiderando o halo amarelo. A inoculação por aspersão resultou em pequeno número de lesões/planta, em razão da desfolha ocorrida anteriormente às avaliações de diâmetro e ao menor número de lesões induzidas/folha nas plantas inoculadas por esse método (Figuras 1 e 2).

As diferenças observadas entre os genótipos, com menores diâmetros de lesões nas plantas de tangerina 'Ponkan' e 'Pêra Rio' estão de acordo com avaliações realizadas tanto em casa-de-vegetação quanto campo, em estudos de resistência varietal ao cancro cítrico (Leite Jr. \& Mohan, 1984). Da mesma forma, menores períodos de incubação e maiores diâmetros são resultantes da inoculação com ferimentos, em comparação com a aspersão da suspensão bacteriana (Garran, 1988; Graham \& Gottwald, 1990; Egel et al., 1991). A inoculação de Xcc por ferimentos também resulta na expressão mais uniforme dos sintomas (Tabela 1; Figuras 1 e 2), como observado também por outros autores (Garran, 1988; Belasque Jr. \& Jesus Jr., 2006). Apesar disso, estimativas do diâmetro de lesões com erros na média inferiores a 3\% são impraticáveis em razão do tamanho

TABELA 1 - Diâmetros médios de lesões de cancro cítrico, com e sem halo amarelo ao redor do tecido necrosado, aos 56, 70 e 83 dias após a inoculação, estimados por dois avaliadores em plantas cítricas de laranjas doces 'Hamlin' e 'Pêra Rio' e tangerina 'Ponkan' inoculadas por ferimentos ou aspersão

\begin{tabular}{|c|c|c|c|c|c|}
\hline \multicolumn{2}{|c|}{ Fontes de variação } & \multicolumn{2}{|c|}{ Com halo amarelo } & \multicolumn{2}{|c|}{ Sem halo amarelo } \\
\hline & & $\begin{array}{l}\text { Diâmetro } \\
(\mathrm{mm})^{1}\end{array}$ & Teste F ( $p)$ & $\begin{array}{l}\text { Diâmetro } \\
\text { (mm) }\end{array}$ & Teste F ( $p)$ \\
\hline \multirow{5}{*}{$\begin{array}{l}\text { Inoculação } \\
\text { Genótipo }\end{array}$} & & \multicolumn{4}{|c|}{56 dias após a inoculação } \\
\hline & $\begin{array}{l}\text { ferimentos } \\
\text { aspersão }\end{array}$ & $\begin{array}{c}4,30 \pm 0,81 \\
-\end{array}$ & - & $\begin{array}{l}2,87 \pm 0,38 \mathrm{a} \\
1,58 \pm 0,43 \mathrm{~b}\end{array}$ & $2191,40(<0,01)$ \\
\hline & 'Hamlin' & $3,96 \pm 0,56 \mathrm{~b}$ & & $2,82 \pm 0,62 \mathrm{a}$ & \\
\hline & 'Pêra Rio’' & $4,01 \pm 0,85 \mathrm{~b}$ & $255,43(<0,01)$ & $2,78 \pm 0,51 \mathrm{a}$ & $173,75(<0,01)$ \\
\hline & 'Ponkan' & $4,91 \pm 0,66 \mathrm{a}$ & & $2,55 \pm 0,48 \mathrm{~b}$ & \\
\hline \multirow[t]{3}{*}{ Avaliador } & 1 & $4,29 \pm 0,82$ & $2,08(0,15)$ & $2,70 \pm 0,56$ & $3,49(0,06)$ \\
\hline & 2 & $4,32 \pm 0,81$ & & $2,75 \pm 0,56$ & \\
\hline & & \multicolumn{4}{|c|}{70 dias após a inoculação } \\
\hline \multirow{5}{*}{$\begin{array}{l}\text { Inoculação } \\
\text { Genótipo }\end{array}$} & ferimentos & $5,62 \pm 0,96$ & - & $3,35 \pm 0,45 \mathrm{a}$ & $1569,40(<0,01)$ \\
\hline & aspersão & - & & $1,95 \pm 0,68 b$ & \\
\hline & 'Hamlin' & $5,59 \pm 1,06$ & & $3,31 \pm 0,71 \mathrm{a}$ & \\
\hline & 'Pêra Rio' & $5,70 \pm 0,96$ & $2,84(0,06)$ & $3,29 \pm 0,56 \mathrm{a}$ & $177,28(<0,01)$ \\
\hline & 'Ponkan' & $5,56 \pm 0,84$ & & $2,98 \pm 0,63 b$ & \\
\hline \multirow[t]{3}{*}{ Avaliador } & 1 & $5,63 \pm 0,97$ & $0,34(0,56)$ & $3,13 \pm 0,61 b$ & $52,33(<0,01)$ \\
\hline & 2 & $5,60 \pm 0,95$ & & $3,26 \pm 0,69 \mathrm{a}$ & \\
\hline & & \multicolumn{4}{|c|}{83 dias após a inoculação } \\
\hline \multirow{5}{*}{$\begin{array}{l}\text { Inoculação } \\
\text { Genótipo }\end{array}$} & ferimentos & $5,74 \pm 1,00 \mathrm{a}$ & $529,29(<0,01)$ & $3,84 \pm 0,42 \mathrm{a}$ & $2259,67(<0,01)$ \\
\hline & aspersão & $3,85 \pm 1,02 b$ & & $2,25 \pm 0,75 b$ & \\
\hline & Hamlin & $5,74 \pm 1,45 \mathrm{a}$ & & $3,74 \pm 0,78 b$ & \\
\hline & Pera & $5,48 \pm 0,92 \mathrm{~b}$ & $60,05(<0,01)$ & $3,88 \pm 0,55 \mathrm{a}$ & $309,23(<0,01)$ \\
\hline & Ponkan & $5,38 \pm 0,98 \mathrm{~b}$ & & $3,37 \pm 0,58 \mathrm{c}$ & \\
\hline \multirow[t]{2}{*}{ Avaliador } & 1 & $5,48 \pm 1,14 b$ & $4,56(0,03)$ & $3,66 \pm 0,68$ & $1,24(0,27)$ \\
\hline & 2 & $5,59 \pm 1,18 \mathrm{a}$ & & $3,68 \pm 0,68$ & \\
\hline
\end{tabular}

${ }^{1}$ Médias seguidas pelas mesmas letras dentro de cada fonte de variação (método de inoculação, genótipo ou avaliador) e data de avaliação não diferem entre si pelo teste de Tukey $(5 \%)$. 
TABELA 2 - Tamanho da amostra, em número de lesões, para estimar o diâmetro de lesões de cancro cítrico em diferentes datas após a inoculação de Xanthomonas citri subsp. citri. Dados referentes a quatro repetições por tratamento e dois avaliadores

\begin{tabular}{|c|c|c|c|c|c|c|c|c|}
\hline \multirow{3}{*}{ Erro na média (\%) } & \multicolumn{4}{|c|}{ Com halo amarelo } & \multicolumn{4}{|c|}{ Sem halo amarelo } \\
\hline & \multicolumn{4}{|c|}{ Dias após a inoculação } & \multicolumn{4}{|c|}{ Dias após a inoculação } \\
\hline & 56 & 70 & 83 & Todas as datas & 56 & 70 & 83 & Todas as datas \\
\hline 1 & 1012 & 1047 & 1147 & 1229 & 627 & 660 & 442 & 591 \\
\hline 2 & 253 & 262 & 287 & 307 & 157 & 165 & 110 & 148 \\
\hline 3 & 112 & 116 & 127 & 137 & 70 & 73 & 49 & 66 \\
\hline 4 & 63 & 65 & 72 & 77 & 39 & 41 & 28 & 37 \\
\hline 5 & 40 & 42 & 46 & 49 & 25 & 26 & 18 & 24 \\
\hline 6 & 28 & 29 & 32 & 34 & 17 & 18 & 12 & 16 \\
\hline 7 & 21 & 21 & 23 & 25 & 13 & 13 & 9 & 12 \\
\hline 8 & 16 & 16 & 18 & 19 & 10 & 10 & 7 & 9 \\
\hline 9 & 12 & 13 & 14 & 15 & 8 & 8 & 5 & 7 \\
\hline 10 & 10 & 10 & 11 & 12 & 6 & 7 & 4 & 6 \\
\hline 11 & 8 & 9 & 9 & 10 & 5 & 5 & 4 & 5 \\
\hline 12 & 7 & 7 & 8 & 9 & 4 & 5 & 3 & 4 \\
\hline 13 & 6 & 6 & 7 & 7 & 4 & 4 & 3 & 3 \\
\hline 14 & 5 & 5 & 6 & 6 & 3 & 3 & 2 & 3 \\
\hline 15 & 4 & 5 & 5 & 5 & 3 & 3 & 2 & 3 \\
\hline 16 & 4 & 4 & 4 & 5 & 2 & 3 & 2 & 2 \\
\hline 17 & 4 & 4 & 4 & 4 & 2 & 2 & 2 & 2 \\
\hline 18 & 3 & 3 & 4 & 4 & 2 & 2 & 1 & 2 \\
\hline 19 & 3 & 3 & 3 & 3 & 2 & 2 & 1 & 2 \\
\hline 20 & 3 & 3 & 3 & 3 & 2 & 2 & 1 & 1 \\
\hline
\end{tabular}

Inoculação po ferimento
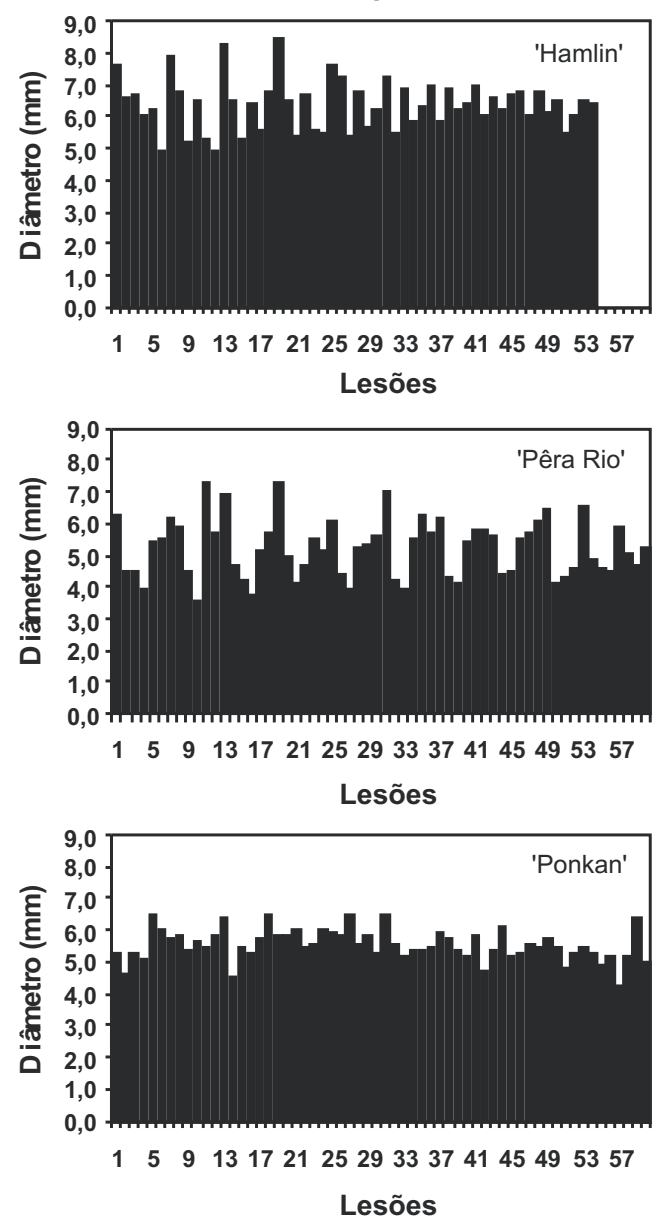
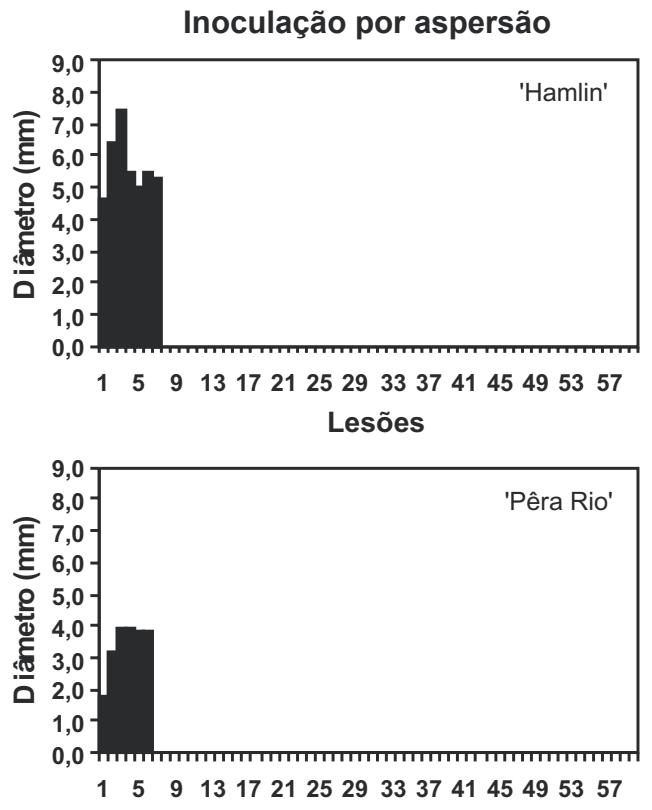

FIG. 1 - Exemplos de diâmetros de todas as lesões de cancro cítrico presentes em uma planta de laranjas doces 'Hamlin' e 'Pêra Rio' e tangerina 'Ponkan', para cada método de inoculação. Os valores de diâmetro correspondem às estimativas do avaliador 1, aos 83 dias após a inoculação, considerando os halos amarelos ao redor do tecido necrosado, quando presentes.

Lesões 

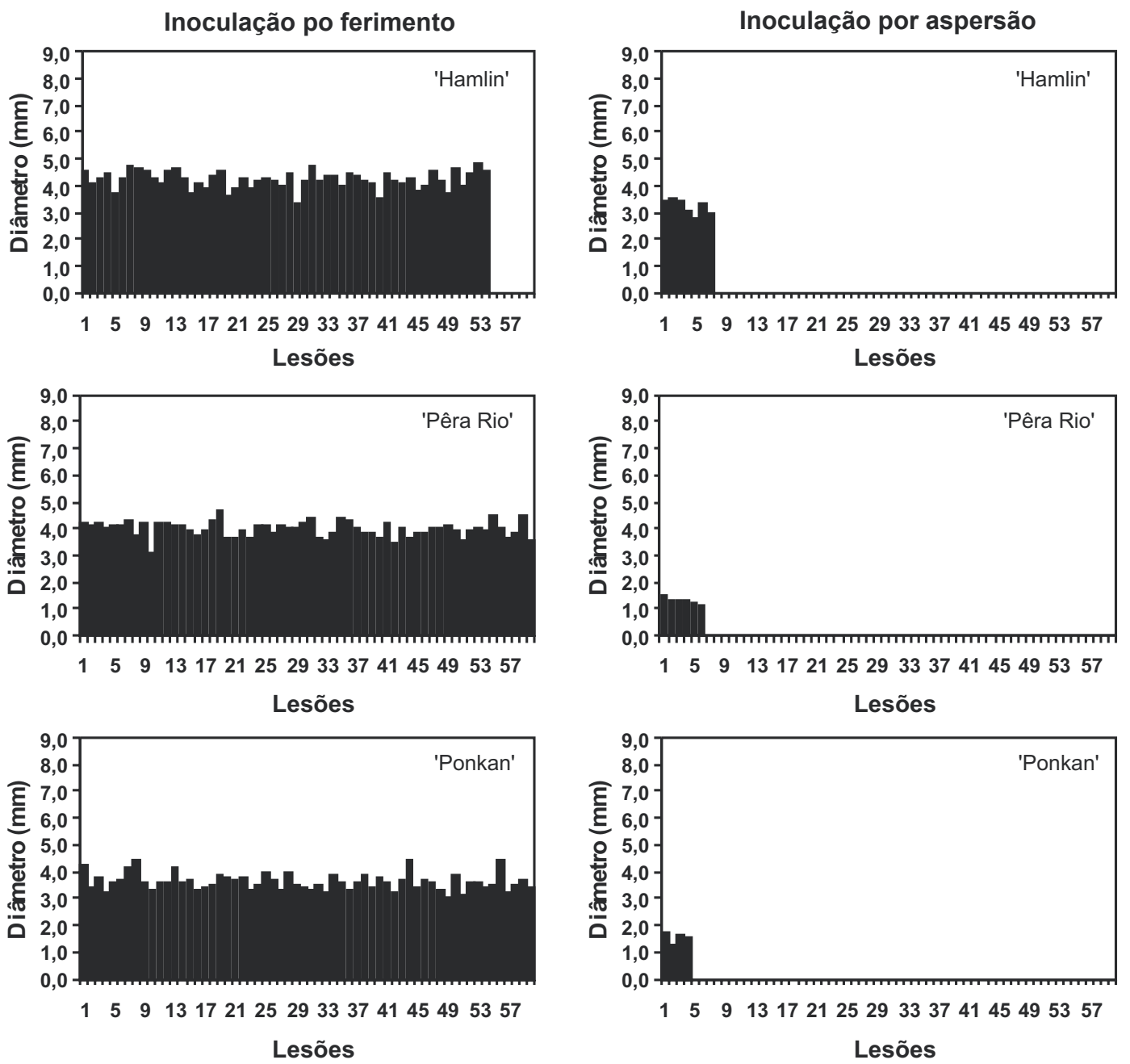

FIG. 2 - Exemplos de diâmetros de todas as lesões de cancro cítrico presentes em uma planta de laranjas doces 'Hamlin' e 'Pêra Rio' e tangerina 'Ponkan', para cada método de inoculação. Os valores de diâmetro correspondem às estimativas do avaliador 1 , aos 83 dias após a inoculação, considerando somente o tecido necrosado.

excessivo da amostra (Tabela 2). Estimativas mais precisas ocorreram nas avaliações tendo-se considerado somente o tecido necrosado. Apesar de o halo amarelo apresentar-se relativamente difuso, tornando assim sua mensuração mais subjetiva, os avaliadores diferiram entre si emigual magnitude nas avaliações com e sem halo amarelo. Estimativas com menores erros na média ocorreram nas avaliações somente do tecido necrosado em razão dos menores diâmetros das lesões. A estimativa das lesões com halo amarelo resultou em diâmetros entre um e dois milímetros maiores (Tabela 1, Figuras 1 e 2). Apesar disso, sempre que possível as estimativas devem considerar o halo amarelo, em razão dos sintomas da doença compreender tanto o tecido necrosado quanto o amarelecimento ao redor da necrose.

$\mathrm{O}$ estudo da resistência de genótipos ao cancro cítrico em casa-de-vegetação ou em laboratório não exclui a necessidade de estudos em campo. Somente no segundo caso podem ser avaliados aspectos relacionados ao crescimento do hospedeiro, freqüência de emissão de novos fluxos vegetativos, influência do porta-enxerto e produção da cultura, dentre outros (Leite Jr. \& Mohan, 1984; Viloria et al., 2004). Mas avaliações prévias em condições controladas facilitam em muito o estudo da resistência, principalmente em programas de melhoramento em razão do excessivo número de genótipos ou progênies (Viloria et al., 2004). Os principais métodos de quantificação do cancro cítrico envolvem o uso de escalas diagramáticas para avaliação da severidade em folhas (Belasque Jr. et al., 2005; Behlau et al., 2008), quantificação do período de incubação (Nociti et al., 2006), incidência de folhas ou frutos sintomáticos (Leite Jr. \& Mohan, 1984; Behlau et al., 2008), contagem do número de lesões (Gottwald et al., 1997; Viloria et al., 2004), estimativa da população bacteriana nas lesões (Egel et al., 1991; Gottwald et al., 1997; Viloria et al., 2004), desfolha 
(Leite Jr. \& Mohan, 1984; Behlau et al., 2008) e o diâmetro de lesões (Graham \& Gottwald, 1990; Egel et al., 1991; Gottwald et al., 1997; Nociti et al., 2006). A inoculação de Xcc por ferimentos e a estimativa do diâmetro de lesões de cancro cítrico pode ser considerado um sistema acurado, preciso, repetível, rápido, e menos custoso na avaliação da interação Xcc-citros e na avaliação da resistência ao cancro cítrico (Garran, 1988; Viloria et al., 2004; Belasque Jr. \& Jesus Jr., 2006). Nesse sentido, considerando os resultados obtidos no presente estudo, estimativas precisas do diâmetro de lesões, com erros na média inferiores a $10 \%$, podem ser obtidas com tamanhos de amostras entre cinco e quinze lesões/planta, independentemente do genótipo, método de inoculação e idade das lesões.

\section{REFERÊNCIAS BIBLIOGRÁFICAS}

Azevedo FA (2005) Transformação genética de citros com os genes bacteriopsina (b0), cecropina e gus. Tese Doutorado - ESALQ, Universidade de São Paulo. Piracicaba, SP.

Barbosa JC, Gimenes-Fernandes N, Massari CA, Ayres AJ (2001) Incidência e distribuição de cancro cítrico em pomares comerciais do Estado de São Paulo e sul do Triângulo Mineiro. Summa Phytopathologica 27:30-35.

Behalu F, Belasque Jr. J, Bergamin Filho A, Graham JH, Leite Jr R (2008) Copper sprays and windbreaks for control of citrus canker on young orange trees in southern Brazil. Crop Protection 27:807813.

Belasque Jr. J, Bergamin Filho A. (2006) Estratégias de controle do cancro cítrico. Summa Phytopathologica 32:S143-S148.

Belasque Jr. J, Jesus Jr WC (2006) Concentração de inóculo e metodologia de inoculação de Xanthomonas axonoppodis pv. citri. Laranja 27:26-272.

Belasque Jr. J, Bassanezi RB, Spósito MB, Ribeiro LM, Jesus Jr WC, Amorim L (2005) Escalas diagramáticas para avaliação da severidade do cancro cítrico. Fitopatologia Brasileira 30:387-393.

Egel DS, Graham JH, Riley TD (1991) Population dynamics of strains of Xanthomonas campestris differing in aggressiveness on Swingle citrumelo and grapefruit. Phytopathology 81:666-671.

Garran SM (1988) Quantitative resistance to the nursery type of citrus canker. M.S. Thesis, University of Florida, Gainesville.

Gottwald TR, Graham JH, Riley TD (1997) The influence of spray adjuvants on exacerbation of citrus bacterial spot. Plant Disease 81:1305-1310.

Gottwald TR, Sun X, Riley T, Graham JH, Ferrandino F, Taylor EL (2002) Geo-referenced spatiotemporal analysis of the urban citrus canker epidemic in Florida. Phytopathology 92:361-377.

Gottwald TR, Timmer LW, Mcguire RG (1989) Analysis of disease progress of citrus canker in nurseries in Argentina. Phytopathology 79:1276-1283.

Graham JH, Gottwald TR Variation in aggressiveness of Xanthomonas campestris pv. citrumelo associated with citrus bacterial spot in Florida citrus nurseries. Phytopathology 80:190196. 1990.

Leite Jr RP, Mohan SK (1984) Evaluation of citrus cultivars for resistance to canker caused by Xanthomonas campestris pv. citri (Hasse) Dye in the State of Paraná, Brazil. Proc. Int. Soc. Citriculture 1:385-389.

Leite Jr RP, Mohan SK, Pereira ALG, Campacci CA(1987) Controle integrado de cancro cítrico - efeito da resistência genética e da aplicação de bactericidas. Fitopatologia Brasileira 12:257-263.

Massari CA, Belasque Jr. J (2006) A campanha de erradicação do cancro cítrico no estado de São Paulo - Situação atual e contaminação em viveiros. Laranja. 27:41-55.

Nociti LAS, Camargo M, Rodrigues Neto J, Francischini FJB, Belasque Jr J (2006) Agressividade de linhagens de Xanthomonas axonopodis pv. aurantifolii tipo C em lima ácida 'Galego'. Fitopatologia Brasileira 31:140-146.

Pavan A (2006) Fusão de protoplastos de citros e avaliação da resistência do híbrido somático laranja 'Hamlin' + mexerica 'Montenegrina' a Xanthomonas axonopodis pv. citri e Xylella fastidiosa. Dissertação Mestrado - ESALQ, Universidade de São Paulo. Piracicaba, SP.

Schaad NW, Postnikova E, Lacy G, Sechler A, Agarkova I, Stromber PE, Stromberg VK, Vidaver AK (2006) Emended classification of xonthomonad patrogens on citrus. Systematic and Applied Microbiology 29:690-695.

Stall RE, Seymour CP (1983) Canker: a threat to citrus in the gulfcoast states. Plant Disease 67:581-585.

Viloria Z, Drouillard DL, Graham JH, Grosser JW (2004) Screening triploid hybrids of 'Lakeland' limequat for resistance to citrus canker. Plant Disease 88: 1056-1060. 